\title{
Correction to: Phenotypic and molecular identification of Brucella suis biotype 1 in a pig from Brazil-case report
}

Acácia Ferreira Vicente ${ }^{1}$ Mateus de Souza Ribeiro Mioni ${ }^{1}$. Didier Quevedo Cagnini ${ }^{2}$. Márcio Garcia Ribeiro ${ }^{1}$. Marcelo Fagali Arabe Filho ${ }^{1}$. Fernando José Paganini Listoni ${ }^{1}$. Bruna Letícia Devidé Ribeiro ${ }^{1}$ · Jane Megid ${ }^{1}$ (1)

Published online: 1 November 2021

c) Sociedade Brasileira de Microbiologia 2021

\section{Correction to: Brazilian Journal of Microbiology https://doi.org/10.1007/s42770-021-00607-y}

In the original version of this article, the given and family names of Acácia Ferreira Vicente were incorrectly structured. The name was displayed correctly in all versions at the time of publication. Moreover, in this article, the affiliation details for Didier Quevedo Cagnini were incorrectly given. The correct affiliation is as below.

Publisher's note Springer Nature remains neutral with regard to jurisdictional claims in published maps and institutional affiliations.

The original article can be found online at https://doi.org/10.1007/ s42770-021-00607-y.

Jane Megid

jane.megid@unesp.br

1 Department of Animal Production and Preventive Veterinary Medicine, Faculty of Veterinary Medicine and Zootechnics, State University of Sao Paulo, Botucatu, SP, Brazil

2 Department of Veterinary Clinical Science, Federal University of Jataí, Jataí, GO, Brazil 